\title{
III.-The Influence of Water on the Availability of Hydrogen Chloride in Alcoholic Solution.
}

By Arthur Lapworth and James Riddick Partington.

IN recent communications by one of the authors, in part with E. Fitzgerald (Trans., 1908, 93, 2167 et seq.), evidence was adduced that during the esterification of a carboxylic acid or the hydrolysis of an ester, as brought about by the catalytic influence of hydrogen chloride, the velocity of reaction was nearly proportional to the concentration of the alcohol and the water respectively, although superficially the velocity of hydrolysis in alcohol or acetone, with a definite concentration of catalyst, appeared to be nearly independent of the concentration of the water over a wide range. The latter effect was attributed to a change in the availability of the catalyst, and was shown to be connected with the observations of Goldschmidt on the retarding influence of water on the esterification of carboxylic acids in alcoholic solution under the influence of mineral acids. Some preliminary experiments were also described which indicated that the phenomena were, as suggested, due in the main to changes in the salt-forming power or availability of the acid acting as catalytic agent, and on measuring the availability of the acid by the use of a weakly basic indicator, it was found that this was greatly altered by small changes in the water-content to an extent which corresponded, in order of magnitude at least, with the simultaneous changes in the velocity of esterification.

Pursuing this train of reasoning, it was demonstrated that the changes in the availability of the acid due to the introduction of water into its solution in alcohol, for example, could not be explained by aid of the view of salt-hydrolysis proposed by Arrhenius, hence, as the power which an acid has of forming complex ions with a weak base of the ammonia type must be proportional to the concentration of free hydrogen ions, other things being equal, it may be inferred that the water acts by diminishing the concentration of the free hydrogen ions if such are present. Consequently water appears to act by uniting with hydrogen ions, as does ammonia, to form complex hydrions. Also, since alcohol and water appear to play similar parts, combination of hydrogen ions with alcohol is probable. With respect to the conception that hydrogen ions unite with water or alcohol, no novelty was claimed, the possibility, even the probability, having been realised by many chemists since the date when the ionic-dissociation hypothesis was first proposed, and especially since the recent development of the oxonium theory. 
Goldschmidt and Udby (Zeitsch. physikal. Chem., 1907, 60, 728) had previously used the conception in discussing the kinetics of accelerated esterification, although theirs was an ad hoc application of the hypothesis, no attempt having been mado by these authors to associate experimentally the anti-catalytic effect of water in esterification processes with alterations in the availability, or salt-forming power, of the acid, and even in applying the conception to the case of a very weak base present in small quantity in an alcoholic solution of hydrogen chloride (loc. cit., p. 731) they picture the hydrated hydrions produced on addition of water as being formed exclusively at the expense of the small amount of salt derived from the weak base (carboxylic acid), which is very far from being the case, as all the salts of weak bases present and the free hydrogen ions, if there, would be diminished in the same proportion.

It is very important to realise that two quite distinct propositions are here involved. The first of these is, that the change in the catalytic activity of a mineral acid in organic solvents, on addition of water, is due to a change in the availability of the mineral acid, and is capable of experimental proof in the manner previously indicated by one of the present authors. The second one concerns the explanation which is to be given of this change in the availability of the mineral acid, and is at present almost wholly hypothetical in character. Fitzgerald and Lapworth, who approached the question from this point of view, were the first to advance the former as a definite proposition, and to indicate the manner in which it might be experimentally established. Goldschmidt and Udby, on the other hand, had previously employed the hypothesis of combination of hydrogen ions with alcohol and water respectively, in explanation of the anti-catalytic effect of water on esterification in alcoholic solution; but as they did not fully realise that the determining factor was the change in the availability of the mineral acid (which naturally depends alwost wholly on the alcohol and the water, and only to an almost inappreciable extent on the small quantity of feebly basic carboxylic acid), they applied the hypothesis in an incorrect manner to the calculation of $\xi$, the concentration of complex hydrions formed by the carboxylic acid (loc. cit., p. 731), entirely overlooking the necessity of taking into consideration the influence of the alcohol used as solvent.

A suggestion made by Goldschmidt and Udby, previously misunderstood by Lapworth, is of great importance in its bearing on the hypothesis of hydrogen ion hydration, and attention may again be drawn to it here. These authors attribute the abnormally large increase in the esterification velocity constant with increasing concentration of catalyst observed in alcohol containing water to the 
removal of part of the free water by combination with part of the catalyst (loc. cit., p. 733-735 and 751 et seq.; compare also Proc., 1909, 25, 19 ; Trans., 1908, 93, 2196 and 2197, where the mass of the free water was assumed nearly constant). This explanation (although, in the generalised form given by these authors, it disregards the well-known stimulating effect of anions on the catalytic action of strong acids) is probably correct so far as it applies to the abnormal case where the concentration of the catalyst and the water are com parable, and further investigation of this particular point would appear to be one of the most promising modes of adducing direct evidence as to the correctness or otherwise of the hypothesis of chemical combination between hydrogen ions and solvent.

The present paper contains an account of work done in the expectation of finding that the determining factor in the influence of water on catalysis by mineral acids in alcoholic solution is the availability of the acid for salt formation. The "availability" of an acid may be defined as a function proportional to its capacity for forming complex hydrions with any mon-acid base, and at any moment the concentration of these complex ions is given by $\xi=k . B P$, where $k$ is a constant for the base in the medium used, $B$ the concentration of the free base, and $P$ the "availability" of the acid, or $P=\frac{\xi}{k \cdot B}$. At present it is only feasible to determine the relative values of $k$ for different bases, hence $P$ here has also only a relative magnitude.*

In order to avoid for the present all hypothesis as to the state of a mineral acid in alcoholic solution, an expression for the change in the availability of a mineral acid in absolute alcohol may be developed on the facts adduced by Goldschmidt and by Goldschmidt and Udby.

These authors found that the velocity of esterification in absolute alcoholic solution was proportional to the number of "hydrogen ions," or with a monobasic mineral acid as catalyst, to the product of its concentration and the degree of dissociation. This, however, is also proportional to the concentration of complex hydrions which the acid would yield with a definite concentration of a free mon-acid base, or, in other words, their work affords the proof that in absolute alcohol the velocity of esterification is ceteris paribus proportional to the availability of the acid as above defined.

Now Goldschmidt and Udby also find that with a given concentration of mineral acid and carboxylic acid, the velocity of esterification is

- The availability here corresponds with the function $R / V \Sigma M \phi$ developed in a previous paper (loc. cit., p. 2195), where $R$ is the degree of dissociation of the acid ; $V=$ the volume which contains one gram-equivalent of acid, $M$ and $\phi$ corresponding with $B$ and $k$ respectively. 
nearly proportional to $\frac{1}{r+w}$, where $r$ is a constant which depends only on the alcohol, and $w$ is the concentration of the water. The contribution which Fitzgerald and Lapworth claim to have made here, is in pointing out that the form of the esterification curve in alcohol departs from the unimolecular type only to the extent that the condition of the catalyst alters, $\frac{1}{r+w}$ being merely a measure of the availability of the catalyst; in other words, the velocity of esterification is proportional to the availability of the catalyst, not only in absolute alcohol, but in moist alcohol too, and $P=\frac{P_{o} r}{r+w}$, where $P_{o}$ is the availability when $w=0$. It may be noted that with any given state of the mixture of alcohol and water the availability is also proportional to the concentration of the catalyst, hence

$$
P=X . c \frac{p \cdot r}{r+w},
$$

where $c=$ the concentration of the catalyst, $p=$ its availability when $c=1$ and $w=0$, and $X=$ the degree of dissociation as measured by the electrical conduetivity method in a medium having that particular composition. For the highly dilute solutions discussed in the following paragraphs, $X$ is assumed constant.

One of the present authors has already shown that this is the conclusion which must be derived if the hypothesis of combination of the hydrogen ions with the alcohol, the water, and the carboxylic acid be adopted (Trans., 1908, 93, 2195), as the availability must be proportional to the concentration of the free hydrogen ions if theso are present.

In order to prove experimentally that this conclusion is the correct one, it is necessary to show that the salt-forming capacity of a very dilute mineral acid varies as $\frac{1}{r+w}$, where $r$ is identical with that calculated from the results of esterification velocity determinations. For the purpose a very weakly basic indicator may be used, and the amount of salt formed with a given concentration of base estimated by colorimetric methods. In practice this is difficult to do, and a somewhat different mode of treatment must be employed, namely, to keep the amount of salt and base nearly constant by varying the concentration of the mineral acid and the water simultaneously. In this case the application of the law of mass action to the definition of availability gives $\xi=k . B . P$, which in terms of the authors' theory is $=k B \cdot \frac{p . c . r}{r+w}$, where $\xi=$ the concentration of the complex hydrions. 
When $\xi$ and $B$ are constant, then $P$ is also constant, consequently $\frac{c}{r+w}$ is a constant, say $K$.

It is shown in the practical part of the paper that (1) in these circumstances $\frac{c}{r+w}$ is experimentally nearly constant for salt formation; and (2) with different indicators the value of $r$ is identical with that obtained by observations on the velocity of esterification, within the limits of experimental error, which, it must be admitted, are at present considerable owing to the very small value of $r$, the measure of the basic affinity of absolute alcohol, and also because of the considerable influence of the merest traces of impurity on the availability of the highly dilute acid which it was necessary to use.

The accurate measurement of the availability of acids in organic media is at present very difficult, owing to circumstances which have already been discussed, and the means which is the most generally applicable, as yet, is that based on determinations of the velocity of esterification, since the basic affinity of alcohols and carboxylic acids is small and less likely to disturb the availability of the highly dilute acid than when indicators, amides, or other definitely basic compounds are introduced; moreover, a carboxylic acid may be chosen to suit a solution of any desired degree of acidity. At the time of the publication of his first paper, and that with E. Fitzgerald, one of us had in view the determination of the availability of acids in various media, simple and mixed, by the electrical method applied in the hydrogen electrode, which, apart from disturbing influences and boundary effects, should theoretically be capable of giving the ratio of the availabilities of an acid in solutions contained in two intercommunicating cells, entirely apart from the reality or otherwise of "free hydrogen ions." Acree has recently drawn attention to the possibility of using the principle of the hydrogen electrode in connexion with experiments on catalysis for the measurement of the concentration of free hydrogen ions (Amer. Chem. J., 1909, 41, 482). It would be most interesting to obtain confirmation by this means of the "availability formula," $P=\frac{k . c .}{r+w}$, for hydrogen chloride in strong alcohol.

The method should also be applicable to the determination of the relative strengths of bases, weaker than water, in alcoholic and other solutions. Such estimation might also be made by using esterification or tintometric processes, as was previously suggested (Trans., 1908, 93, 2199 ), but in connexion with the preliminary numbers previously given, it is necessary to state that the method of determination 


\section{LAPWORTH AND PARTINGTON : INFLUENCE OF WATER ON}

employed necessarily leads to quite discrepant values for the affinities of very weak bases, owing to a number of sources of error which were not realised at that time. It was assumed, for example, that most of the base added was in the free state, which is by no means the case when a base such as carbamide competes with alcohol for the acid; moreover, the presence of traces of basic impurities in the material will affect the availability of even a relatively large quantity of an acid when this happens to be one which is feebly ionised, as is the case with trichloroacetic acid in benzene, and our experiments show clearly how difficult it is to be certain that basic impurities in important quantities are absent. With a fuller realisation of these and other points of difficulty it is proposed to undertake the study of affinity constants of some very weak bases in alcoholic solution, in the hope of devising trustworthy methods of measurement.

The hydrogen electrode may also prove useful in investigating the changes in the availability of acids in acetone and in ether. In these, which, as is well known, are poor ionising solvents for hydrogen chloride, acids behave in a remarkable manner towards the first traces of moisture. In pure dry acetone, the first small additions of water do not cause any marked fall in the availability of dissolved hydrogen chloride, although with larger amounts the availability falls off much as it does in alcohol, as is indicated by the numbers given by Fitzgerald and Lapworth for ester hydrolysis and for esterification in moist acetone. In dry ether, again, a very small quantity of water actually causes a decided increase in the availability. These points were first noted during experiments which Mr. Fitzgerald has been conducting on the velocity of esterification in initially dry acetone and ether; here abnormalities were observed in the esterification curve with the former as solvent, while with the latter the curves showed a point of inflexion; tintometric experiments confirmed the conclusion that this was a phenomenon dependent on the availability of the catalyst, and were of interest as adding some weight to the contention that the much discussed changes in the velocity of esterification are due to static causes not connected with the mechanism of reaction except in so far as the availability of the catalyst is concerned.

Experiments on the application of the hydrogen electrode to these questions are now in progress.

\section{EXPERIMENTAL.}

The alcohol employed in these determinations was prepared from five distinct specimens, $A, B, C, D$, and $E$. $A$ was made from a sample of 96 per cent. spirit by beating it with lime for three days, and subsequently treating the resulting nearly dry alcohol with excess of 
calcium. Samples $B, C ; D$, and $E$ were made from three different specimens of commercial absolute alcohol. In all cases the last traces of moisture were removed by heating the alcohol with a considerable excess of calcium turnings until a sample of the liquid on addition of water set to a jelly-like mass, indicating that calcium ethoxide was present, and the dried liquid was then directly distilled, the vapour being passed through a trap containing glass wool, the first and last portions rejected, and the middle fraction collected in a dried flask provided with a soda-lime tube to ensure the absence of moisture. The test applied for the presence of calcium ethoxide afforded full proof that the dehydration was as complete as the process was capable of effecting; and further treatment with calcium was obviously superfluous; this conclusion was confirmed by the approximate constancy of the low water value of the four specimens of alcohol obtained in this manner.

\section{Tintometric Experiments.}

Aminoazobenzene is an extremely sensitive indicator to hydrogen chloride in absolute alcohol, and was only suitable for concentrations of acid between $N / 10,000$ and $N / 100,000$, so that errors due to traces of impurities were liable to be unreasonably large. Many other indicators were tried, but the only one having a very decided advantage over aminoazobenzene was an azo-derivative of diphenylamine, the sensitiveness of which was considerably less than that of aminoazobenzene. Further investigation may lead to the discovery of still less basic indicators, more useful than these, for investigations in such solvents as absolute alcohol with higher concentrations of mineral acid.

The principle of the method used throughout has already been discussed; the procedure was to run a definite volume of a solution of alcoholic hydrogen chloride into the absolute alcohol under investigation, partly to discharge the colour by addition of a minute quantity of water, and then to restore the original tint by adding more of the alcoholic hydrogen chloride.

The alcoholic hydrogen chloride and the water were measured from narrow, graduated tubes discharging the liquid from a capillary exit; these tubes had been carefully calibrated, and the errors in reading the small volumes of liquid and those due to alterations in bulk of the original alcohol under investigation were usually within the limits of the experimental error due to other causes. The discrepancies at first were very marked, of ten leading to differences of 25 per cent. in the "water value" for any specimen of absolute alcohol, and this was finally traced to the effect of the laboratory air with which the 
solutions were unavoidably brought into contact during the operation of thoroughly mixing the added acid or water. When the solutions were stirred in the ordinary way with a bent glass rod, it was noticed, especially with the extremely dilute solution of hydrogen chloride employed and with aminoazobenzene as indicator, that very decided changes in the colour occurred in the tintometer, indicating a diminution in the acidity of the solutions. This was due mainly neither to carbon dioxide nor aqueous vapour, as pure dry carbon dioxide had no appreciable influence, and the laboratory air, after being passed through a tube of lime or soda-lime, still produced the same effect. If air dried over sulphuric acid was used to stir the solution, however, the tint did not change, so that the effect was doubtless due to traces of ammonia or some other powerfully basic impurity in the atmosphere. Further, the solutions, if undisturbed or stirred by twisting a spiral glass rod in the solution, did not alter in tint appreciably during the time occupied in an experiment, so that the latter method was finally adopted when using the tubes of a colorimeter to contain the specimens of alcohol.

In all cases 50 c.c. of the specimen of absolute alcohol were used, but three distinct modes of measurement were employed, the temperature of the alcohol in all cases being within two degrees of $25^{\circ}$, except when it is stated otherwise.

(1) The alcohol containing the indicator was contained in a 50 c.c. flask, and alcoholic hydrogen chloride having the same concentration of indicator as the original alcohol was added until the tint was as nearly as possible identical with that in a standard specimen in a similar flask; water was then introduced, and more alcoholic hydrogen chloride to restore as nearly as possible the original tint, this process being repeated several times, the added volume noted in each case, and the water value of the alcohol determined by a graphic method or by the method of least squares.

(2) The alcohol with a trace of indicator was contained in one of the tubes of a colorimeter and tinted by alcoholic hydrogen chloride to nearly the same colour as that of the liquid in the standard tube of the instrument, the exact depth of the standard liquid required to produce a balance being noted. After addition of a measured volume of water, more hydrogen chloride solution was added, and the tint balanced by varying the depth of the standard solution. More hydrogen chloride was then added, the tint again balanced, and so on until a reasonably large number of readings had been made; in this case the depth of the standard solution was found experimentally to be proportional to the hydrogen chloride present when the amount of water was constant, so that the corrections were easily applied.

(3) As in (2), but much more indicator was employed, and the tint 
was viewed through a deep blue screen. The depth of the standard liquid was not proportional to the amount of hydrogen chloride in the alcohol, so that separate experiments had to be made to determine the correction formula.

In cases (2) and (3) the water values were at first estimated by a modification of the method of least squares, but this was afterwards abandoned, as they could be obtained graphically within the limits of experimental error.

It will be unnecessary to go into detail in each case, but one or two typical instances of each kind may be given, with the object of indicating the mode of calculation, as well as to show that the formula $P=\frac{k c}{r+w}$ applies here.

\section{TYPE I.}

Indicator : Aminoazobenzene. Hydrochloric acid $=N / 100$ nearly. $W=$ water present in c.c.

$H=$ volume of alcoholic hydrogen chloride added in c.c.

$A=$ total volume of alcohol.

$h=\frac{H}{A} A_{0}$, or quantity of acid per 50 c.c. of alcohol.

$R$ = the water value, in grams, of 50 c.c. of the alcohol used. $W^{\prime}=\frac{50 \mathrm{~W}}{A}$, or the amount of water per 50 c.c. of alcohol. $C=\frac{h}{W^{\prime}+R}$

\begin{tabular}{|c|c|c|c|c|c|}
\hline$W$ & $H$. & A. & $h$. & $W^{\prime}$. & $C$ \\
\hline 0.00 & $1 \cdot 00$ & $51 \cdot 0$ & $1 \cdot 00$ & 0.000 & $10 \cdot 3$ \\
\hline 0.09 & $2 \cdot 00$ & $52 \cdot 0$ & $1 \cdot 96$ & 0.086 & $10 \cdot 7$ \\
\hline $0 \cdot 18$ & $2 \cdot 83$ & 528 & 273 & $0 \cdot 171$ & 10.2 \\
\hline 0.36 & $4 \cdot 70$ & $54 \cdot 7$ & $4 \cdot 31$ & 0.329 & \\
\hline 0.72 & $8 \cdot 40$ & $58 \cdot 4$ & $7 \cdot 34$ & 0.616 & 3 \\
\hline
\end{tabular}

$R=$ water value per 50 c.c. of the alcohol at $25^{\circ}=0.097$ gram, whence $r=10.8$.

For the applicability of the formula $P=\frac{k c}{r+w}$ (see above), the value of $C$ should be constant.

\section{TyPe III.}

Indicator : $p$-Tolueneazodiphenylamine, used with blue screen. Strength of alcoholic hydrogen chloride added was between $N / 5$ and $N / 10$. (In these cases no correction was needed for the relatively small volume of alcoholic hydrogen chloride added, which did not amount to more than 2 per cent. of the total volume of alcohol used.)

$W=$ c.c. of water present (in 50 c.c. of alcohol). 
$H=$ volume of alcoholic hydrogen chloride in c.c.

$l=$ height of adjustable column of standard liquid in $\mathrm{cm}$.

A series of measurements showed that under the conditions and within the limits used, the product $H \times\left(\frac{1}{l}-0.04\right)$ was constant with absolute alcohol, or with alcohol containing any fixed concentration of water. Hence this product was equal to $H_{o} \times\left(\frac{1}{l_{0}}-0.04\right)$, where $H_{o}$ is the volume of alcoholic hydrogen chloride which would be necessary to produce any standard tint corresponding with the fixed height, $l_{o}$.

As $\left(\frac{1}{l_{o}}-0.04\right)$ is constant, then for any two observations the relation between the amounts of acid $H_{o}$ and $H_{o}^{\prime}$ required to produce a standard tint was given by $\frac{H_{o}}{H_{o}^{\prime}}=\frac{H \times\left(\frac{1}{l}-0.04\right)}{H \times\left(\frac{1}{l^{\prime}}-0.04\right)}$; or the product $H \times\left(\frac{1}{l}-0.04\right)$ is proportional to the amount of hydrogen chloride required to produce any definite standard tint with a fixed watercontent.

Two instances are given. The first to indicate the applicability of the foregoing correction formula, and the second to demonstrate that the formula $H_{o}=(r+w) \times a$ constant is applicable when the water varies in amount, and, therefore, $P=\frac{k}{r+w}$ when the amount of hydrogen chloride is constant (compare p. 23).

\section{Example I.}

\begin{tabular}{|c|c|c|c|c|c|}
\hline$W$ & $l$. & $B$. & $H$. & $H \times B$ & C. \\
\hline 0.0 & $7 \cdot 85$ & 0.0876 & 0.25 & 0.0219 & $2 \cdot 38$ \\
\hline 0.0 & $8 \cdot 40$ & 0.0790 & $0 \cdot 28$ & 0.0221 & $2 \cdot 40$ \\
\hline 0.0 & $8 \cdot 95$ & 0.0717 & 0.30 & 0.02151 & $2 \cdot 33$ \\
\hline 0.074 & $8 \cdot 35$ & 0.0798 & 0.50 & 0.0399 & $2 \cdot 40$ \\
\hline 0.074 & $8 \cdot 70$ & 0.0749 & $c \cdot 53$ & 0.0397 & $2 \cdot 39$ \\
\hline 0.074 & $8 \cdot 95$ & 0.0717 & 0.55 & 0.0394 & $2 \cdot 37$ \\
\hline 0.221 & $8 \cdot 10$ & 0.0835 & 0.90 & 0.07515 & $2 \cdot 40$ \\
\hline 0.221 & $8 \cdot 55$ & 0.0770 & 0.97 & 0.0748 & $2 \cdot 39$ \\
\hline $0 \cdot 221$ & $8 \cdot 85$ & 0.0730 & $1 \cdot 04$ & 0.0759 & $2 \cdot 42$ \\
\hline
\end{tabular}

The water value, $R$, of 50 c.c. of the alcohol used was $=0.092$ gram The column headed $B$ contains the values of $\left(\frac{1}{l}-0.04\right)$, and $C$, those of $\frac{H \times B}{R+W}$.

The applicability of the correction formula $H \times\left(\frac{1}{l}-0.04\right)$ is shown by the close agreement between the bracketed values of $H \times B$. 
The applicability of the availability formula $P=k \frac{c}{r+w}$ is shown by the approximate constancy in the values of $C$ throughout.

Example II.

$\begin{array}{lclllc}W . & l . & B . & H . & H \times B . & C . \\ 0.0 & 8.40 & 0.0790 & 0.165 & 0.01304 & 1.37 \\ 0.0 & 8 \cdot 79 & 0.0738 & 0.18 & 0.0133 & 1.40 \\ 0.0 & 9.62 & 0.0641 & 0.20 & 0.01282 & 1.35 \\ 0.0552 & 8 \cdot 73 & 0.0745 & 0.29 & 0.0216 & 1.44 \\ 0.0552 & 9.03 & 0.0707 & 0.30 & 0.0212 & 1.41 \\ 0.1935 & 7.89 & 0.0867 & 0.46 & 0.0399 & 1.38 \\ 0.2655 & 7.55 & 0.0925 & 0.53 & 0.0490 & 1.36 \\ 0.3519 & 7.62 & 0.0912 & 0.68 & 0.0620 & 1.39 \\ 0.4329 & 7.87 & 0.0871 & 0.85 & 0.0740 & 1.40 \\ 0.486 & 8.47 & 0.0781 & 1.01 & 0.0789 & 1.36\end{array}$

$R$, or water value, $=0.095$ gram for 50 c.c. of the absolute alcohol, whence $r=0.106$ (or 1 litre of the absolute alcohol used was equivalent to 0.106 gram-molecules of water at $25^{\circ}$ ).

\section{Esterification Experiments.}

For the determination of the water value of the alcohol by the esterification process, purified phenylacetic acid dried in a vacuum over sulphuric acid was employed in all cases. The flasks employed were subjected to the action of a current of steam for a quarter of an hour, and then carefully dried before each experiment. The dry acid was only roughly measured, but the water in each case was weighed. From each sample of alcohol a solution of hydrogen chloride of about $N / 10$ strength was prepared by passing the dried gas into a portion of the specimen, care being taken to exclude moisture. The alcoholic solutions before admixture were all first heated to the temperature of the thermostat, and the moment when the reaction commenced was noted. One or two titrations were always made near the commencement of the reaction for the purpose of obtaining the true initial titre by extrapolation, as this value was required for a knowledge of the exact amount of water present at any stage. The titre of the hydrogen chloride present at the beginning and end of each experiment was taken, using $N / 100-$ silver nitrate, thus definitely ensuring constancy in the amount of catalyst.

Two flasks were always examined simultaneously, one containing the initially dry alcohol, and the other, alcohol containing initially a weighed quantity of water.

The intermediate values of the constants being the most trustworthy, the approximate water value of the alcohol is best gauged by comparing the intermediate values of the constants obtained for the two flasks. That is to say, the value of $r$ was not ascertained by the reference to 
the constancy of the value for any one experiment, but by comparing the numbers obtained in the two experiments.

This method commends itself as the best, since the more trustworthy values for the velocity are of course those calculated from the time when the change has become steady to a point not far from balf way towards the end. All the titres, $y$, are corrected for the hydrochloric acid present.

The bracketed values of the titre $y$ for $T=0$ were obtained by graphic extrapolation from the first fow observations, for which no constant was calculated. $R$ was calculated throughout from the formula corresponding with that used by Goldschmidt and Udby as

$$
-\frac{d y}{d t}=k c \cdot \frac{y}{R+W+y_{o}-y}
$$

when the concentration of the catalyst is constant,

whence $\quad k c=\frac{\left(R+W+y_{0}\right)\left(\log _{e} y_{1}-\log _{e} y\right)-\left(y_{1}-y\right)}{T^{\prime}-T_{1}}$,

where $R=$ the water equivalent of 10 c.c. of the alcohol used in $N / 10$ c.c.

$W=$ the equivalent of the initially added water.

$y=$ the titre of 10 c.c. of the solution at the time $T$.

$y_{0}=$ initial titre [bracketed value] of 10 c.c. of the solution calculated by extrapolation.

$y_{1}=$ the first titre actually made at the time $T_{1}$.

The time is given in minutes, and the titres are c.c. of $N / 10$-alkali required to neutralise the free phenylacetic acid present in 10 c.c. of the solution investigated.

$(r$ in all cases in this paper refers to the water equivalent in grammolecules of one litre of alcohol.)

\section{Esterification Results for Specimen A.}

Each flask had a capacity of 100 c.c. Amount of solution used for each titre $=10$ c.c. Time in minutes. Titre given in c.c. of $N / 10$-sodium hydroxide. Hydrochloric acid during reaction was $00195 \mathrm{~N}$, nearly.

Flask I. - No water.

\begin{tabular}{|c|c|c|c|c|c|}
\hline \multirow{10}{*}{$\begin{array}{r}T . \\
{[0} \\
7 \\
29 \\
42 \\
68 \\
137 \\
212 \\
287\end{array}$} & & \multicolumn{4}{|c|}{$k c$, assuming } \\
\hline & $\begin{array}{c}y \cdot \\
0 \cdot 0: 31\end{array}$ & $r=0.15$. & $r=0 \cdot 11$ & $r=0.10$. & $r=0.09$ \\
\hline & $\begin{array}{l}9 \cdot 931 \\
9.50\end{array}$ & $=$ & - & 二 & 二 \\
\hline & $8 \cdot 32$ & - & - & - & - \\
\hline & $7 \cdot 63$ & - & - & - & - \\
\hline & $6 \cdot 47$ & $10 \cdot 74$ & $8 \cdot 23$ & $7 \cdot 61$ & $6 \cdot 95$ \\
\hline & $4 \cdot 44$ & $10 \cdot 68$ & $8 \cdot 36$ & $7 \cdot 77$ & $7 \cdot 17$ \\
\hline & 3.09 & $10 \cdot 51$ & $8 \cdot 31$ & $7 \cdot 80$ & $7 \cdot 24$ \\
\hline & $2 \cdot 18$ & 10.49 & $8 \cdot 38$ & $7 \cdot 89$ & $7 \cdot 34$ \\
\hline & Mean......... & $10 \cdot 61$ & $8 \cdot 32$ & $7 \cdot 77$ & $7 \cdot 18$ \\
\hline
\end{tabular}


AVAILABILITY OF HYDROGEN CHLORIDE.

Flask II. -Water $=0.36$ gram.

\begin{tabular}{|c|c|c|c|c|c|}
\hline \multirow{2}{*}{$T$} & \multirow[b]{2}{*}{$y$} & \multicolumn{3}{|c|}{$k c$, assuming } & \multirow[b]{2}{*}{$r=0.09}$. \\
\hline & & $r=0.15$. & $r=0 \cdot 11$. & $r=0 \cdot 10$ & \\
\hline$[0$ & $20 \cdot 2]$ & - & - & - & - \\
\hline 15 & $19 \cdot 50$ & - & -- & - & - \\
\hline 30 & 18.81 & - & - & - & - \\
\hline 69 & $17 \cdot 10$ & $8 \cdot 96$ & $7 \cdot 87$ & $7 \cdot 76$ & $7 \cdot 50$ \\
\hline 138 & $14 \cdot 52$ & $9 \cdot 16$ & $8 \cdot 21$ & $7 \cdot 96$ & $7 \cdot 70$ \\
\hline 216 & $12 \cdot 30$ & $9 \cdot 08$ & $8 \cdot 11$ & $7 \cdot 91$ & $7 \cdot 68$ \\
\hline 446 & $7 \cdot 91$ & $8 \cdot 86$ & 8.04 & $7 \cdot 82$ & $7 \cdot 59$ \\
\hline & Mean.......... & $9 \cdot 02$ & $8 \cdot 06$ & $7 \cdot 87$ & $7 \cdot 62$ \\
\hline
\end{tabular}

The value of $r$ evidently lies between $0 \cdot 10$ and $0 \cdot 11$.

A series of tintometric experiments for this specimen of absolute alcohol gave $r=$ (i) $0.105,0.101,0.105$.

(ii) $0.093,0.101$.

(iii) $0 \cdot 105,0 \cdot 101,0 \cdot 101,0 \cdot 095$.

Series B.-Each flask had a capacity of 50 c.c. Amount of solution used for each titration $=10$ c.c. Time in minutes. Titre given in c.c. $N / 10$-sodium hydroxide. Hydrochloric acid during reaction was $0.0140 \mathrm{~N}$, nearly.

Flask I.-With no water.

\begin{tabular}{rccccc}
$r$. & $y$. & \multicolumn{5}{c}{$k c$, assuming } \\
\cline { 3 - 6 }$[0$ & $11 \cdot 43]$ & $-0 \cdot 15$. & $r=0 \cdot 11$. & $r=0 \cdot 10$. & $r=0 \cdot 09$. \\
12 & $10 \cdot 80$ & - & - & - & - \\
98 & $7 \cdot 52$ & $7 \cdot 32$ & $5 \cdot 63$ & $5 \cdot 21$ & $4 \cdot 77$ \\
220 & $5 \cdot 02$ & $6 \cdot 95$ & $5 \cdot 48$ & $5 \cdot 11$ & $4 \cdot 73$ \\
303 & $3 \cdot 75$ & $7 \cdot 17$ & $5 \cdot 73$ & $5 \cdot 36$ & $\frac{5 \cdot 00}{5 \cdot 43}$
\end{tabular}

Flask II.-With $0 \cdot 18$ gram of water.

\begin{tabular}{|c|c|c|c|c|c|}
\hline \multirow{7}{*}{$\begin{array}{r}T . \\
{[0} \\
10 \\
95 \\
205 \\
300\end{array}$} & \multirow[b]{2}{*}{$y$. } & \multicolumn{4}{|c|}{$k c$, assuming } \\
\hline & & $r=0.15$. & $r=0.11$. & $r=0 \cdot 10$. & $r=0.09$. \\
\hline & $10 \cdot 50]$ & - & - & - & - \\
\hline & $10 \cdot 30$ & - & - & - & - \\
\hline & 8.88 & $6 \cdot 28$ & $5 \cdot 57$ & $5 \cdot 40$ & $5 \cdot 23$ \\
\hline & $7 \cdot 30$ & $6 \cdot 49$ & $5 \cdot 77$ & $5 \cdot 61$ & $5 \cdot 43$ \\
\hline & $6 \cdot 26$ & $6 \cdot 41$ & $5 \cdot 74$ & $5 \cdot 56$ & $5 \cdot 39$ \\
\hline & Mean.......... & $6 \cdot 39$ & $5 \cdot 69$ & $5 \cdot 52$ & $5 \cdot 35$ \\
\hline
\end{tabular}

The value of $r$ evidently lies just above 0:11.

Tintometric measurements gave $r=\left\{\begin{array}{l}\text { (ii) } 0.098,0 \cdot 106,0 \cdot 108 \text { (iii) } 0.108,0.098,0 \cdot 100 .\end{array}\right.$

Series C.-Each flask had a capacity of 50 c.c. Amount of solution used for titration $=10$ c.c. Time in minutes. Titre given in c.c. of 
$N / 10$-sodium hydroxide. Hydrochloric acid during reaction was $0.0182 N$.

Flask I. -No water.

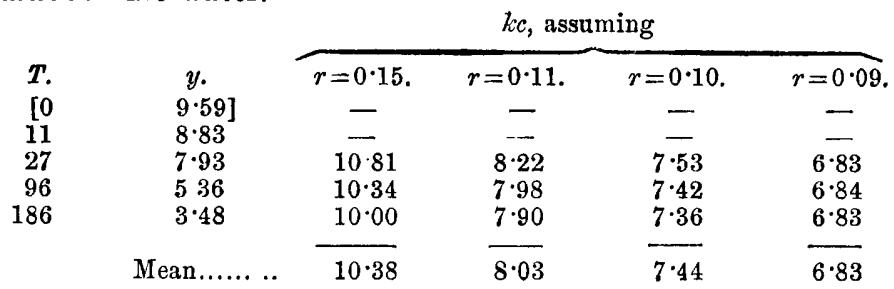

Flask II.-Water $=0 \cdot 1430$ gram.

\begin{tabular}{|c|c|c|c|c|c|}
\hline \multirow{7}{*}{$\begin{array}{r}T . \\
{[0} \\
22 \\
67 \\
260 \\
487\end{array}$} & \multirow[b]{2}{*}{$y$. } & \multicolumn{4}{|c|}{$k c$, assuming } \\
\hline & & $r=0.15$. & $r=0.11$ & $r=0 \cdot 10$ & $r=0.09$. \\
\hline & $12 \cdot 70]$ & - & - & - & - \\
\hline & 11.73 & - & - & - & - \\
\hline & $10 \cdot 35$ & $9 \cdot 04$ & $7 \cdot 93$ & $7 \cdot 64$ & $7 \cdot 38$ \\
\hline & 6.43 & $8 \cdot 80$ & $7 \cdot 79$ & $7 \cdot 54$ & $7 \cdot 28$ \\
\hline & $3 \cdot 85$ & $8 \cdot 76$ & $7 \cdot 77$ & $7 \cdot 50$ & $7 \cdot 27$ \\
\hline & Mean.......... & $8 \cdot 87$ & $7 \cdot 83$ & $7 \cdot 56$ & $7 \cdot 31$ \\
\hline
\end{tabular}

From above, $r$ is evidently between $0 \cdot 10$ and $0 \cdot 11$.

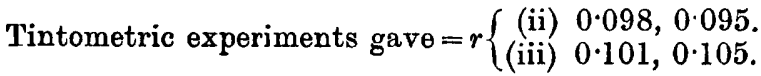

Series D.-Each flask had a capacity of 100 c.c. Amount of solution titrated $=10$ c.c. Time in minutes. Titres in terms of $N / 10$-sodium hydroxide. Hydrochloric acid during reaction was $0.0278 \mathrm{~N}$, nearly.

Flask I.-No water. $\quad$ Flask II.-Water $=0.10$ gram. Flask III.-Water $=0.20$ gram.

\begin{tabular}{|c|c|c|c|c|c|c|c|c|}
\hline$T$ & & $\begin{array}{c}k c \\
(r=0 \cdot 10) .\end{array}$ & $T$ & $y$. & $\begin{array}{c}k c \\
(r=0 \cdot 10) .\end{array}$ & $T$. & y. & $\begin{array}{c}k c \\
(r=0 \cdot 10)\end{array}$ \\
\hline$[0$ & $13 \cdot 33]$ & - & {$[0$} & $13 \cdot 331$ & - & [ & $13 \cdot 33]$ & - \\
\hline 14 & $12 \cdot 05$ & 一 & 18 & $12 \cdot 30$ & - & 2 & $12 \cdot 47$ & - \\
\hline 42 & $9 \cdot 71$ & - & 44 & $10 \cdot 69$ & - & 4 & 11. & $\longrightarrow$ \\
\hline 66 & $8 \cdot 19$ & 0.987 & 71 & $9 \cdot 16$ & 0.986 & 7 & & 0.987 \\
\hline 26 & $5 \cdot 65$ & $1 \cdot 006$ & 131 & $6 \cdot$ & 0.9 & 13 & $7^{\circ}$ & $1 \cdot 001$ \\
\hline 21 & $3 \cdot 48$ & 0.985 & 225 & $4 \cdot 50$ & $1 \cdot 001$ & 227 & $5 \cdot 43$ & $1 \cdot 007$ \\
\hline
\end{tabular}

Tintometric experiments gave $r=0.09$ and 0.11 by (i).

Series E.-Each flask had a capacity of 100 c.c. Amount of solution titrated $=10$ c.c. Time in minutes. Titres in terms of $N / 10$-sodium hydroxide. Hydrochloric acid during reaction was $0.0201 N$, nearly. 
Flask I.-No water. $\quad$ Flask II.-Water $=0.197$ gram.

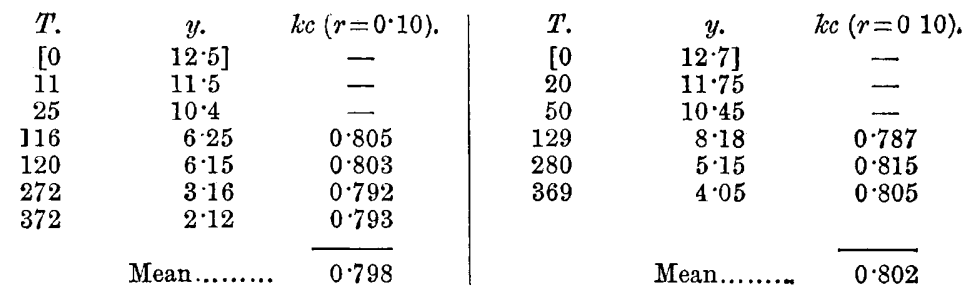

whence $r$ is almost exactly $0 \cdot 10$.

Tintometric experiments gave $r=\left\{\begin{array}{l}\text { (ii) } 0.090,0.089 . \\ \text { (iii) } 0.095,0.098,0.090 \text {. }\end{array}\right.$

The apparent discrepancy between the values of $r$ found, as above, and the value 0.15 used by Goldschmidt and Udby is apparently due mainly to the circumstance that they calculated the value for higher concentrations of catalyst. A comparison of the numbers for the velocity of reaction at low concentrations indicates that the alcohol used by these authors was probably as dry as that used in the experiments detailed in the present paper.

\section{Summary.}

(i) The "availability" of a very dilute solution of hydrogen chloride in moist alcohol is nearly an inverse linear function of the amount of water present for quantities of water not exceeding a concentration of $N / 2$.

(ii) The effect is a static one, and there is no reason to believe that the anti-catalytic effect of water is due to any other cause than a change in the availability of the acid ; it is not, for instance, to any appreciable extent the result of any influences, such as increase in viscosity, tending to lower the measured velocity of reaction (on this point compare, however, S. F. Acree, Amer. Chem. J., 1909, $41,471)$, nor is it the result of ester hydrolysis.

(iii) The availability within the above range may be very nearly represenued by $c \cdot \frac{k}{v+w}$, where $c=$ concentration of the hydrogen chloride, $k$ being a constant, $w$ the concentration of water present, $r$ being the water equivalent of the alcohol present.

(iv) $r$ is a constant which depends on the alcohol (as Goldschmidt and Udby have demonstrated in the case of esterification), but, within the limits of experimental error, is the same whether the availability of the acid be measured by means of esterification velocities or by estimating the amount of the salt which the acid can form with a weak mon-acid base.

VOL. XCVII. 
(v) For absolute alcohol dried over excess of calcium, $v$ is about 0.10 for very low concentrations of hydrogen chloride at $25^{\circ}$; thus, at this temperature, the availability of hydrochloric acid in absolute alcohol is lowered 50 per cent. by the addition of 1.8 grams of water per litre of alcohol.

(vi) If any free hydrogen ions exist in solutions of acids in water or alcohol, an assumption for which there is at present no direct evidence, then for small changes in the composition of the mixture of water and alcohol it may be concluded that the coucentration of these is a measure of the availability of the acid.

(vii) The fundamental differen se between the view of Goldschmidt and Udby and that of Fitzgerald and Lapworth revolves on the point that the first-named workers, although realising that the catalyst is mostly shared between the alcohol and the water, neglected to consider the change in the availability of the catalyst when water is added to its alcoholic solution, and consequently they formed an incorrect conception of the manner in which water would affect the equilibrium between a dissolved weak base and its salt.

The authors desire to state that most of the cost of this investigation was defrayed by a grant from the Government Grant Research Fund of the Royal Society, and for this they wish to express their indebtedness.

SChUNCK IAABoratory, University of Manchester. 